\title{
High intensity focused ultrasound cyclocoagulation in dogs with primary glaucoma: a preliminary study
}

\author{
Pierre-François Isard ${ }^{1, *}$, Marielle Mentek ${ }^{1,2}$, David Clément ${ }^{3}$, Aurélie Béglé ${ }^{3}$, Fabrice Romano ${ }^{4}$, Florent Aptel ${ }^{5}$, \\ Iona Mathieson ${ }^{6}$ and Thomas Dulaurent ${ }^{1}$ \\ ${ }^{1}$ Centre Hospitalier Vétérinaire, 275 Route Impériale, 74370 Saint-Martin Bellevue, France \\ ${ }^{2}$ Menicon Co. Ltd, Innovation Center, Fondation pour Recherches Médicales, Geneva, Switzerland \\ ${ }^{3}$ EYE TECH CARE, 2871 Avenue de l'Europe, 69140 Rillieux-la-Pape, France \\ ${ }^{4} 404$ Rue du Prieuré, 01700 Beynost, France \\ ${ }^{5}$ Department of Ophthalmology, University Hospital of Grenoble, Grenoble Alpes University, 38043 Grenoble, \\ France \\ ${ }^{6}$ Eyevet Referrals, 41-43 Halton Station Road, Sutton Weaver, Cheshire WA7 3DN, United Kingdom
}

\begin{abstract}
The objective was to assess the effect of high intensity focused ultrasound (HIFU) on intraocular pressure (IOP) in dogs with primary glaucoma (PG). Seven dogs (13 eyes) presenting with PG as diagnosed by a raised IOP (> $20 \mathrm{~mm}$ $\mathrm{Hg}$ ) associated with consistent gonioscopy and ultrasound biomicroscopy of the ciliary cleft, with no other ocular disease. Patients were divided into 3 groups, corresponding to their pre-operative IOP (group 1 ranging from 21 to 30 $\mathrm{mm} \mathrm{Hg}$, group 2 from 31 to 40 and group 3 for 40 and above). Ciliary process sonication was achieved with a probe containing one high-frequency transducer operating at $21 \mathrm{MHz}$ during 5 seconds. Six sites were treated in patients from group 1, 8 in group 2, 10 in group 3, under general anesthesia. Post-operative treatment consisted of systemic meloxicam and topical carbonic anhydrase inhibitors, beta-blockers and prostaglandins analogues. No intraoperative complications were observed. Conjunctival hyperaemia occurred in eyes from group 2 (66\%) and 3 (100\%). Conjunctival burns were visible in 2 patients from group 3. One patient from group 3 experienced a hypertensive spike during the first hours post-op with associated pain. The hypotensive effect of HIFU was observed in all groups. Normotensive IOP $(\leq 20 \mathrm{~mm} \mathrm{Hg})$ was reached in all patients until the last recheck at 6 months post op. Despite the small number of patients included in the study, HIFU appears to be a promising option for the management of PG in dogs.
\end{abstract}

Keywords: Ciliary cleft, Dog, Primary glaucoma, Sonication, Surgery.

\section{Introduction}

The canine glaucomas are defined as a group of ocular diseases whose common feature is the death of the retinal ganglion cells, associated with an increase in intraocular pressure (IOP) (Plummer et al., 2013). Elevated IOP occurs when the egress of aqueous humor through the conventional outflow pathway is impeded (Plummer et al., 2013). Canine glaucomas are usually divided into primary, secondary or congenital glaucoma (Plummer et al., 2013). Primary glaucoma (PG) is defined as an elevated IOP with no other concurrent eye disease. It can affect both eyes simultaneously or asynchronously, and exhibits a breed predisposition (Read et al., 1998; Wood et al., 1998; Bjerkas et al., 2002; Kato et al., 2006; Strom et al., 2011; Plummer et al., 2013; Boillot et al., 2014; Fricker et al., 2016; Bedford, 2017). Structural abnormality of the conventional outflow pathway comprising the pectinate ligament, the uveal and corneoscleral trabecular meshworks and the ciliary cleft (Read et al.,
1998; Wood et al., 1998; Bjerkas et al., 2002; Kato et al., 2006; Strom et al., 2011; Plummer et al., 2013; Fricker et al., 2016; Bedford, 2017), or an abnormal biochemical metabolism of the trabecular meshworks (Hassel et al., 2007; Weinstein et al., 2007; Mackay et al., 2008a, 2008b;), may be responsible for PG. Many surgical techniques have been described to manage PG, acting either on the production (De Roetth, 1965; Brightman et al., 1982; Hardman and Stanley, 2001; Lutz and Sapienza, 2009a; Azoulay et al., 2011; Harrington et al., 2013) or the egress of aqueous humor (Cullen et al., 1998; Cullen, 2004), or both at the same time (Sapienza and van der Woerdt, 2005; Lutz and Sapienza, 2009b; Amagai et al., 2014).

Cyclocryothermy (De Roetth, 1965; Brightman et al., 1982), transscleral cyclophotocoagulations (TSCP) (Hardman and Stanley, 2001; Sapienza and van der Woerdt, 2005; Amagai et al., 2014) and endocyclophotocoagulation (ECP) (Lutz and Sapienza, 2009a,b; Azoulay et al., 2011; Harrington et al., 2013)

*Corresponding Author: Pierre-François Isard. Centre Hospitalier Vétérinaire, 275 Route Impériale, 74370 Saint-Martin Bellevue, France. Tel.: +33 (0)4 506009 00; Fax: +33 (0)4 506014 86. Email: pf.isard@ chvsm.com 
are the most common cyclodestructive techniques. Cyclocryothermy consists of non-selectively freezing the ciliary process with a nitrous oxide or liquid nitrogen probe applied in direct contact with the bulbar conjunctiva, overlying to the ciliary processes (De Roetth, 1965; Brightman et al., 1982). This technique has become progressively obsolete and was mainly used to reduce IOP in blind patients with persistent pain. Transscleral diode or Nd: YAG laser cyclophotocoagulations have been studied in veterinary medicine (Hardman and Stanley, 2001; Sapienza and van der Woerdt, 2005; Amagai et al., 2014). They aim to destroy the ciliary processes with focused laser energy. As with cyclocryothermy, the probe is applied trans-sclerally through the bulbar conjunctiva over the ciliary processes. Although the duration of effect on the normalization of the IOP remains variable with these techniques, TSLCP remains widely used in the management of PG. ECP is a more recent technique which aims to selectively destroy the ciliary processes via an intraocular approach (Lutz and Sapienza, 2009a,b; Azoulay et al., 2011; Harrington et al., 2013). Although it requires further studies to implement standardized procedures, ECP seems a promising surgery. Anterior chamber shunt implantations are the leading techniques aiming at facilitating the outflow of aqueous humor. The purpose of these shunts is to create a new discharge chamber, bypassing the abnormal conventional outflow pathways. As for the cyclodestructive surgeries, many different procedures and materials have been described to facilitate aqueous humor drainage, with varying results (Cullen et al., 1998; Cullen, 2004; Sapienza and van der Woerdt, 2005; Lutz and Sapienza, 2009b). Glaucoma surgeries, used alone or in combination, offer a maximum duration effect of several months to one or two years (Plummer et al., 2013). Dose-effect relationship remains difficult to predict with the current cyclodestructive techniques. Consequently, severe complications such as IOP rebound spike, chronic inflammation, cataract formation, phtisis bulbi and corneal ulcers, are frequent (De Roetth, 1965; Brightman et al., 1982; Hardman and Stanley, 2001; Sapienza and van der Woerdt, 2005; Lutz and Sapienza, 2009a,b; Azoulay et al., 2011; Harrington et al., 2013; Amagai et al., 2014). High intensity focused ultrasound (HIFU) aims to selectively destroy the ciliary process, using ultrasonic energy instead of the light energy provided by Laser technologies. The use of HIFU in the treatment of glaucoma in humans was first described in the eighties with promising results (Coleman et al., 1985a,b, 1986; Burgess et al., 1986). Temporarily abandoned because of the size of the device and the time required for the procedure, HIFU has recently sparked again the interest of ophthalmologists (Aptel et al., 2011, 2014b, 2016; Denis et al., 2015). Evolution of the technologies led to the manufacturing of smaller and more efficient devices, allowing safer and shorter procedures (Charrel et al., 2011). The purpose of the present study was to evaluate the efficacy and safety of HIFU in dogs with PG.

\section{Animal recruitment \\ Materials and Methods}

Seven dogs with PG of one or both eyes at the Ophthalmology Department of the Centre Hospitalier Vétérinaire Saint-Martin (Saint-Martin Bellevue, France), were included in the study. All dogs underwent a complete ophthalmic examination (Slit Lamp, STT), an IOP measurement (Tonovet ${ }^{\circledR}$, Icare, Finland), ultrasound biomicroscopy (UBM) with a 35 $\mathrm{MHz}$ probe (VuMax®, Sonomed Escalon, EDC LAMY, Carvin, France), and conventional ultrasound examination of the posterior segment with a $20 \mathrm{MHz}$ probe (VuMax®), Sonomed Escalon, EDC LAMY, Carvin, France). In patients with a clear cornea, nonmydriatic indirect ophthalmoscopy and gonioscopy were also performed. Inclusion criteria were dogs with a raised IOP $(\geq 21 \mathrm{~mm} \mathrm{Hg})$ and a narrow or closed ciliary cleft as observed by UBM and/or gonioscopy with no concurrent anomaly of the posterior segment as observed by conventional $20 \mathrm{MHz}$ ultrasound. Exclusion criteria were any other identifiable causes of secondary glaucoma.

\section{HIFU device}

The HIFU device used in this study was adapted from a human device that has previously been described (Aptel et al., 2010; Charrel et al., 2011). The EYE TECH CARE Company (Rillieux-la-Pape, France) modified the machine for veterinary use. It was then composed of a coupling cone made of polymer filled with saline solution, centered on the cornea in contact with the patient's conjunctiva. A probe containing an active piezoelectric element was inserted in the upper part of the coupling cone and immersed in the saline solution. The transducer containing the piezoelectric ceramic was a segment of a $10.2 \mathrm{~mm}$ radius cylinder with a $4.5 \mathrm{~mm}$ width and a $7 \mathrm{~mm}$ length. The focal volume of the transducer had an approximately elliptic cylinder shape. The position of the ceramic into the probe was defined to accurately fit with the canine eye anatomy (data provided by the manufacturer). Thus, the ultrasound beam emitted by the probe was selectively targeted on the ciliary processes of the canine patient to be treated. The resonant frequency of the transducer was $21 \mathrm{MHz}$.

\section{Surgical procedure}

Meloxicam was administered intravenously prior to surgery to limit intraocular inflammation associated with the surgery. Topical anesthesia was achieved by 5 consecutive instillations of oxybuprocaine chlorhydrate (Cébésine ${ }^{\circledR} 0.4 \%$, Chauvin, Montpellier, France) at 30 second intervals. General anesthesia was induced by IV 
injection of medetomidine $(2 \mu \mathrm{g} / \mathrm{kg})$ (Domitor ${ }^{\circledR}$, Vetoquinol, Lure, France), ketamine (5 $\mathrm{mg} / \mathrm{kg}$ ) (Imalgene ${ }^{\circledR}$, Merial, Lyon, France), and morphine (0.3 $\mathrm{mg} / \mathrm{kg}$ ) (Lavoisier, Paris, France), followed by inhalation of isoflurane gas (1.5 to 3\% of an air mixture of $30 \%$ - oxygen $70 \%$ ) (Vetflurane ${ }^{\circledR}$, Virbac, Carros, France). The anaesthetised dog was positioned in dorsal or lateral recumbency with its head stabilized in a hollow cushion, as for an intraocular surgery. The combination probe / coupling cone of the HIFU device was available in three sizes $(16,18,20 \mathrm{~mm})$, corresponding to the different sizes of eyeballs to be treated. The operator selected the coupling cone size matching the palpebral aperture of the patient being treated (Fig. 1A). Once the coupling cone was centered on the patient's cornea, it was manually held by the operator. The corresponding probe was then inserted in the upper part of the cone (Fig. 1B). The cavity created between the eye surface of the patient, the edge of the coupling cone and the probe was filled with $5 \mathrm{~mL}$ of sterile saline, through the central aperture of the device (Fig. 2).
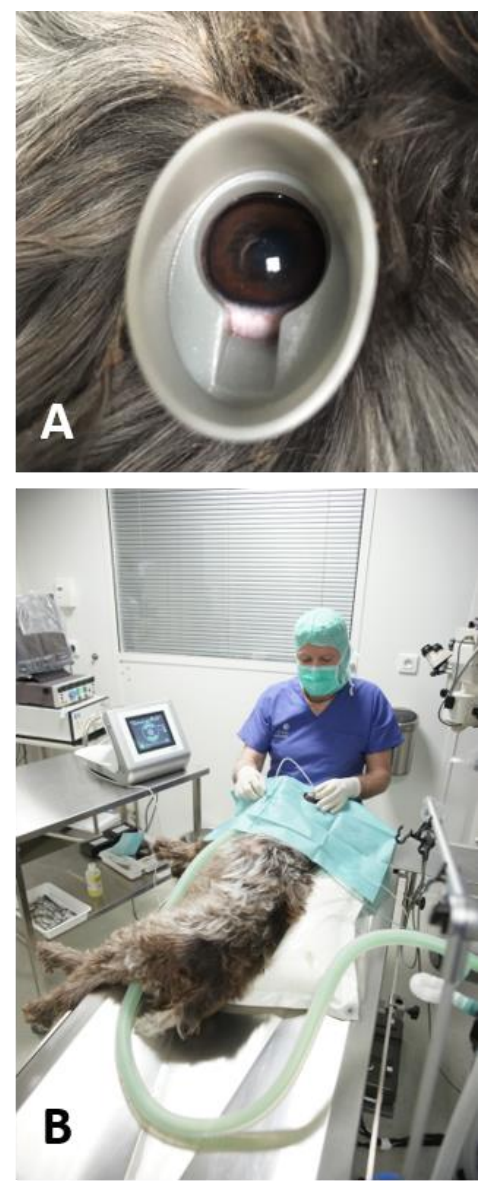

Fig. 1. (A): Coupling cone inserted into the palpebral fissure of the patient being treated. The aperture of the coupling cone had to be centered on the cornea so that the ultra sound beam reached precisely the ciliary processes. (B): General view of the device.

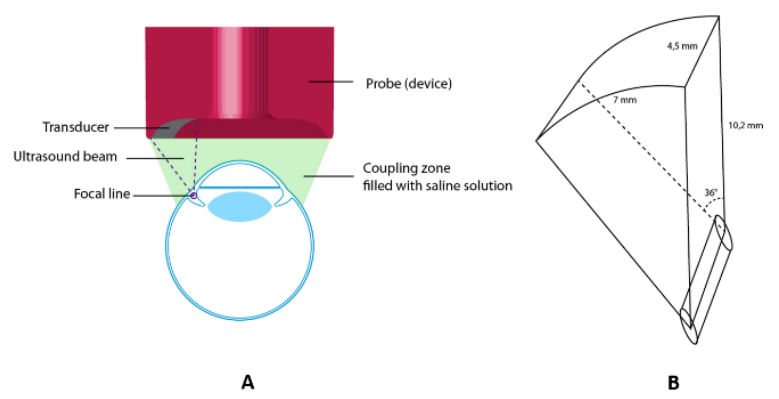

Fig. 2. (A): Schematic cross section of the High Intensity Focused Ultrasound device. The veterinary probe contains only one transducer. (B): Schematic representation of the focal volume associated with the piezoelectric ceramic.

All patients were treated with the transducer activated for 5 seconds at $2.4 \mathrm{~W}$ acoustic power. Eyes were divided in three groups, depending on the preoperative IOP: Group 1 with IOP ranging from 21 to $30 \mathrm{~mm} \mathrm{Hg}$, Group 2 with IOP ranging from 31 to $40 \mathrm{~mm} \mathrm{Hg}$ and Group 3 with IOP higher than $40 \mathrm{~mm} \mathrm{Hg}$. As the time of ultrasound delivery could not be set with the veterinary device and fixed to 5 seconds, it was arbitrarily decided to increase the number of treated sites in relation to the degree of preoperative IOP elevation. We assumed that the number of treated sites would correlate to the effect on the IOP, as would the time of ultrasound delivery (Denis et al., 2015). In each group a specific number of sites were thus treated: 6 sites for group 1, 8 sites for group 2 and 10 sites for group 3, avoiding the 3 o'clock and the 9 o'clock positions to prevent direct damage to the long posterior ciliary blood vessels (Brightman et al., 1982).

Both eyes of patients bilaterally affected were treated during the same session. Patients of the study were hospitalized for 24 hours. The IOP was measured at $6 \mathrm{~h}$ and $24 \mathrm{~h}$ postoperatively during the hospitalization period. At each IOP measurement, a complete ophthalmic examination was performed to identify potential side effects associated with the procedure. In all eyes, the post-operative treatment consisted of topical dorzolamide / timolol maleate combination BID (Cosopt ${ }^{\circledR}$, MSD, Courbevoie, France), topical latanoprost $\mathrm{BiD}$ (Xalatan ${ }^{\circledR}$, Pfizer, Paris, France) and systemic meloxicam $0.1 \mathrm{mg} / \mathrm{kg} \quad$ (Metacam ${ }^{\circledR}$, Boehringer Ingelheim, Paris, France) for one week.

\section{Follow-up}

Follow-up examinations were performed at 7, 21, 90 and 180 days post-surgery and consisted of a complete ophthalmic examination and IOP measurement. Topical medical treatment was continued until the end of the follow-up period.

\section{End point and statistical analysis}

Surgical success was defined as an IOP less than or equal to $20 \mathrm{~mm} \mathrm{Hg}$, with no clinical signs of ocular pain at the last follow-up examination. All IOP data were 
expressed as median and min, max values. Statistical analysis was performed using GraphPad Prism (GraphPad Software, La Jolla, CA, USA). Normality of data was assessed using Shapiro-Wilk normality tests. Considering the non-Gaussian distribution of the data and the small number of animals per group, treatment group and time effects were assessed using the nonparametric Friedman test. Post hoc analysis was conducted with Dunn's test. P-values $<0.05$ were considered statistically significant.

\section{Patients' characteristics}

\section{Results}

An overview of the 7 patients in which the HIFU cyclocoagulation was used is presented in Table 1, showing breed, gender, age, affected eye, ongoing antiglaucomatous therapies prior to referral, IOP at initial presentation and evaluation of dazzle reflex and menace response.

A series of 13 eyes from 7 dogs was included in the study. The mean age of affected dogs was 7 years, ranging from 4 to 11 years. Six different breeds were represented. There were 4 males and 3 females. The procedure was performed in both eyes in 6 patients and in the right eye in one. Ongoing ocular treatment prior to referral included beta-blockers, carbonic anhydrase inhibitors, prostaglandins analogs and pilocarpine. Four eyes had mixed treatment. One eye had no treatment prior to referral. Median IOP prior to the surgery was $28 \mathrm{~mm} \mathrm{Hg}(\min 21 \mathrm{~mm} \mathrm{Hg}$ and max 59 $\mathrm{mm} \mathrm{Hg}$ )

\section{Safety and efficacy of the procedure}

There were no intraoperative complications during the procedure. One dog (the Shiba Inu) encountered an ocular hypertensive spike in both eyes during the first hours post-surgery (baseline IOP $+13 \mathrm{~mm} \mathrm{Hg}$ in OD and baseline $\mathrm{IOP}+7 \mathrm{~mm} \mathrm{Hg}$ in OS). This patient underwent a new HIFU procedure with a particular attention to the probe positioning. No signs of pain were visible during the immediate post-operative period except for the patient with an ocular hypertension spike, which presented with epiphora and blepharospasm.

Transient conjunctival hyperaemia was visible in 2 eyes from group 2 (66\%) and in all eyes from group 3. Well circumscribed conjunctival burns corresponding to the treated sites were visible in 2 eyes from group $3(66 \%)$. Those immediate postoperative complications resolved with additional vaseline ointment (Pommade Vitamine A Dulcis, Allergan, Pringy, France) and were no longer visible at the first follow-up examination at day 7 . Median, min, max and relative IOP reductions of each group and of all patients are shown in Table 2.

\section{Effect of the treatment group on the IOP}

There was a significant global effect of the treatment group on IOP reduction when comparing the 3 groups $(\mathrm{p}<0.0001)$, supporting that IOP reduction is a function of the initial level of IOP and the number of treatment sites. Multiple comparisons reveal a higher IOP decrease in group 3 compared to group $1(\mathrm{p}=0.0009)$, meaning that the greater the number of treated sites, the greater the lowering effect on IOP.

\section{Effect of the sonication procedure over time}

There was a significant decrease of IOP after treatment in group 1 ( $\mathrm{p}=0.0003)$. IOP decrease in group 2 and 3 did not reach statistical significance.

Figure 3 illustrates the evolution of IOP over time for each group. Long term post-operative evaluation of vision was consistent with preoperative data in all patients with no visual deterioration at the completion of the follow-up period.

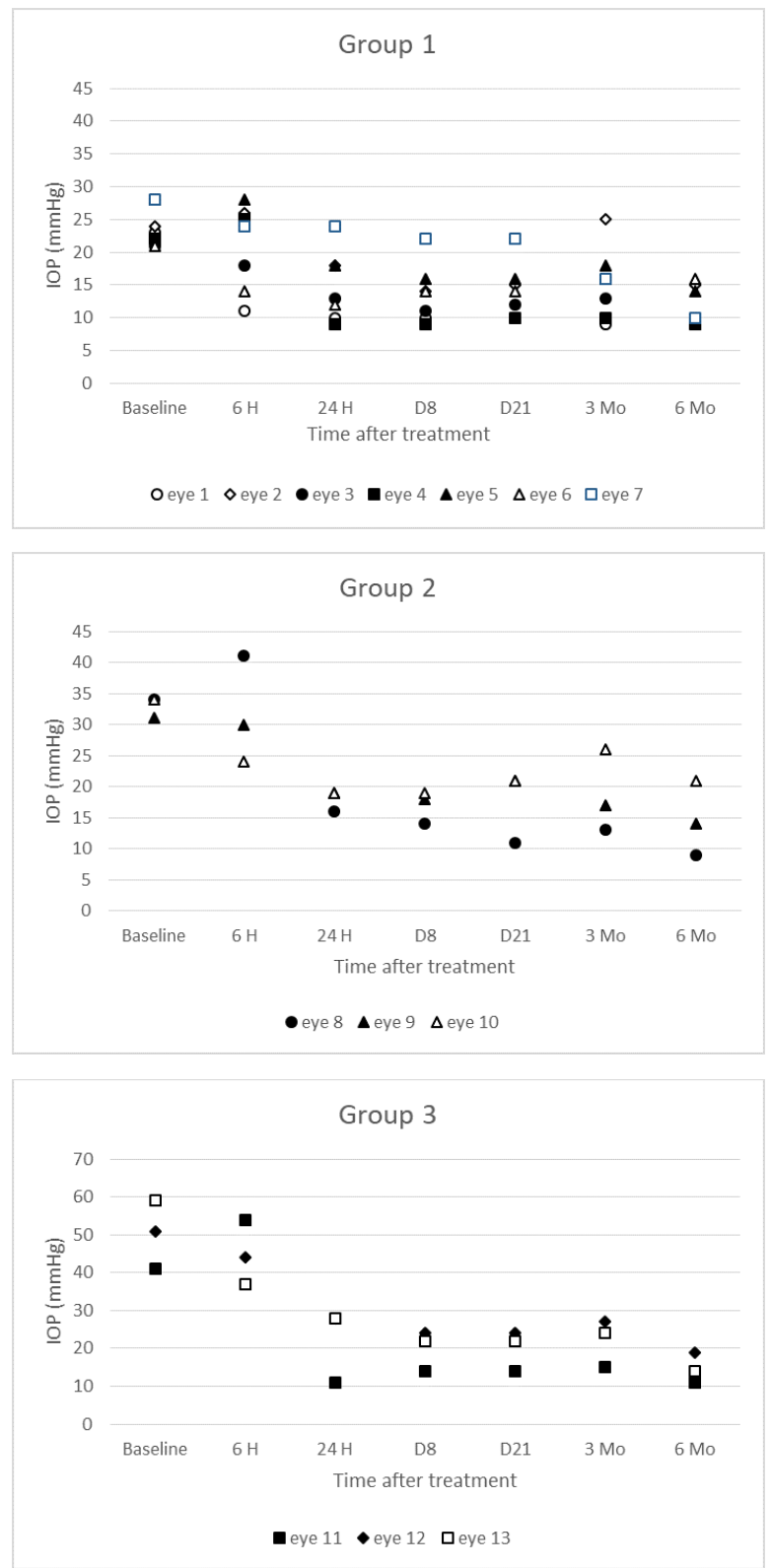

Fig. 3. Evolution of Intraocular pressure over time for each group. 
Table 1. Summary of patient data with regards to breed, gender, age, affected eye, ongoing preoperative treatment, Intra Ocular Pressure at initial presentation, vision tests results, and corresponding groups.

\begin{tabular}{|c|c|c|c|c|c|c|c|c|c|}
\hline Breed & Gender & Age & $\begin{array}{c}\text { Affected } \\
\text { eye }\end{array}$ & $\begin{array}{l}\text { Medical treatment } \\
\text { prior to referal }\end{array}$ & $\begin{array}{l}\text { IOP at initial } \\
\text { presentation }\end{array}$ & $\begin{array}{l}\text { Dazzle } \\
\text { Reflex }\end{array}$ & $\begin{array}{l}\text { Menace } \\
\text { response }\end{array}$ & $\begin{array}{c}\text { Corresponding } \\
\text { group }\end{array}$ & Eye \# \\
\hline \multirow{2}{*}{$\begin{array}{l}\text { Jack Russel } \\
\text { Terrier }\end{array}$} & \multirow{2}{*}{ M } & \multirow{2}{*}{9} & OD & Dexamethasone & 23 & 1 & 1 & 1 & Eye 1 \\
\hline & & & OS & Dexamethasone & 51 & 1 & 0 & 3 & Eye 12 \\
\hline \multirow{2}{*}{ Siberian Husky } & \multirow{2}{*}{ M } & \multirow{2}{*}{7} & OD & Timolol Maleate & 24 & 1 & 1 & 1 & Eye 2 \\
\hline & & & OS & Timolol Maleate & 21 & 1 & 1 & 1 & Eye 3 \\
\hline \multirow{2}{*}{ French Bulldog } & \multirow{2}{*}{ NF } & \multirow{2}{*}{1} & OS & Pilocarpine & 22 & 1 & 1 & 1 & Eye 4 \\
\hline & & & OD & Pilocarpine & 31 & 1 & 1 & 2 & Eye 9 \\
\hline \multirow{2}{*}{$\begin{array}{l}\text { American } \\
\text { Cocker Spaniel }\end{array}$} & \multirow{2}{*}{$\mathrm{F}$} & \multirow{2}{*}{11} & OD & Timolol Maleate & 28 & 1 & 1 & 1 & Eye 5 \\
\hline & & & OS & Timolol Maleate & 21 & 1 & 1 & 1 & Eye 6 \\
\hline \multirow{2}{*}{$\begin{array}{l}\text { Labrador } \\
\text { Retriever }\end{array}$} & \multirow{2}{*}{ M } & \multirow{2}{*}{7} & OS & $\begin{array}{l}\text { Timolol Maleate, } \\
\text { Dorzolamide }\end{array}$ & 28 & 1 & 1 & 1 & Eye 7 \\
\hline & & & OD & $\begin{array}{l}\text { Timolol Maleate, } \\
\text { Dorzolamide }\end{array}$ & 59 & 1 & 0 & 3 & Eye 13 \\
\hline \multirow{2}{*}{ Shiba Inu } & \multirow{2}{*}{ NF } & \multirow[t]{2}{*}{7} & OS OD & $\begin{array}{l}\text { Timolol Maleate, } \\
\text { Dorzolamide, } \\
\text { 41Latanoprost }\end{array}$ & 34 & 1 & 1 & 2 & Eye 8 \\
\hline & & & OD & $\begin{array}{l}\text { 34Timolol Maleate, } \\
\text { Dorzolamide, Latanoprost }\end{array}$ & 41 & 1 & 1 & 3 & Eye 11 \\
\hline French Bulldog & M & 8 & & No treatment & 34 & 1 & 1 & 2 & Eye 10 \\
\hline
\end{tabular}

(M): Male; (NF): Neutered Female; (F): Female; (OD): Right Eye; (OS): Left Eye; (IOP): Intraocular Pressure.

Table 2. Median, Min-Max and relative IOP reductions of each group (mm Hg: Millimeters of Mercury, IOP: Intra Ocular Pressure, H: hours, D: Day, Mo: Month).

\begin{tabular}{lcccccc}
\hline & \multicolumn{2}{c}{ Group 1, $\mathrm{n}=7$ eyes } & \multicolumn{2}{c}{ Group 2, $\mathrm{n}=3$ eyes } & \multicolumn{2}{c}{ Group 3, $\mathrm{n}=3$ eyes } \\
\cline { 2 - 7 } Time & $\begin{array}{c}\text { IOP Median } \\
\text { [Min-Max], } \\
\mathrm{mm} \mathrm{Hg}\end{array}$ & $\begin{array}{c}\text { Relative IOP } \\
\text { Reduction, } \%\end{array}$ & $\begin{array}{c}\text { IOP Median } \\
{[\text { Min-Max] }} \\
\mathrm{mm} \mathrm{Hg}\end{array}$ & $\begin{array}{c}\text { Relative IOP } \\
\text { Reduction, } \%\end{array}$ & $\begin{array}{c}\text { IOP Median } \\
\text { [Min-Max], } \\
\mathrm{mm} \mathrm{Hg}\end{array}$ & $\begin{array}{c}\text { Relative IOP } \\
\text { Reduction, \% }\end{array}$ \\
\hline Baseline & $23[21-28]$ & - & $34[31-34]$ & - & $51[41-59]$ & - \\
6 H & $24[11-28]$ & $13.2 \pm 23.4$ & $30[24-41]$ & $4.0 \pm 25.0$ & $44[37-54]$ & $6.4 \pm 35.1$ \\
\hline $24 \mathrm{H}$ & $13[9-24]$ & $38.8 \pm 16.0$ & $19[16-19]$ & $45.3 \pm 7.2$ & $28[11-28]$ & $56.9 \pm 14.5$ \\
D 7 & $14[9-22]$ & $43.2 \pm 13.1$ & $18[14-19]$ & $48.3 \pm 9.2$ & $22[14-24]$ & $60.5 \pm 6.7$ \\
D 21 & $14[10-22]$ & $41.3 \pm 12.1$ & $21[11-21]$ & $46.0 \pm 18.9$ & $22[14-24]$ & $60.5 \pm 6.7$ \\
Mo 3 & $16[9-25]$ & $36.0 \pm 21.5$ & $17[13-26]$ & $43.5 \pm 19.2$ & $24[15-27]$ & $56.6 \pm 8.5$ \\
Mo 6 & $10[9-16]$ & $49.7 \pm 14.4$ & $14[9-21]$ & $55.5 \pm 17.7$ & $14[11-19]$ & $70.7 \pm 7.1$ \\
\hline
\end{tabular}

\section{Discussion}

The aim of the present study was to evaluate the hypotensive effect of HIFU delivered by a miniaturized transducer on the ciliary processes of dogs affected by PG. The use of HIFU in the treatment of refractory glaucoma was described in humans in the eighties (Coleman et al., 1985a,b, 1986; Burgess et al., 1986). Although it showed a promising IOP reduction in glaucomatous patients, this technique was progressively abandoned. The equipment needed was bulky, the time of the procedure was long (up to 2 hours), and the rate of ocular complications was relatively high, probably due to the low frequency of the original device $(5 \mathrm{MHz})$ and the inaccuracy of the probe positioning.
The technology providing the HIFU was recently optimized and modernized (EYE TECH CARE, Rillieux la Pape, France) with a miniaturized device adapted to the anatomy of the human eye. It is available in three different sizes and allows a shorter treatment time of approximately 2 minutes at a higher frequency (21MHz) (Charrel et al., 2011). It was further modified by the manufacturer for canine ocular anatomy, so that the ultrasound beam was focused precisely on the ciliary processes. For economic reasons, the veterinary prototype consisted of a single piezoelectric ceramic (vs 6 in the human device) thus treating one site at a time. Furthermore, the duration of US delivery can be set in the human device, whereas it was fixed to 5 seconds in the veterinary one. 
The mechanism leading to IOP reduction has been assessed by histologic and UBM imaging studies on animals and humans (Valtot et al., 1990; Polack et al., 1991; Aptel et al., 2010, 2014a). Coagulative necrosis (loss of ciliary epithelium, vascular congestion, distension of the collagen fibers) and secondary cystic involution of the ciliary bodies are the main consequences of focused ultrasounds, thus resulting in decreased aqueous humor production. Hyporeflective suprachoroidal spaces were also observed postoperatively by UBM in human patients and in rabbits, suggesting increased uveoscleral outflow through the suprachoroidal space (Aptel et al., 2011, 2014a). When properly targeted over the ciliary body, the focused ultrasound beam does not damage the adjacent ocular structures or produce intraocular inflammation (Aptel et al., 2010), consistently with our clinical findings which did not reveal any postoperative intraocular inflammation.

The procedure was overall well tolerated in canines. Ocular pain was observed in one patient, who also experienced bilateral ocular hypertension. As the other patients did not exhibit signs of pain or hypertensive spikes, we hypothesized that pain was linked to the elevated IOP and not with the procedure itself. The cause of the rebound effect (RE) after sonication remains unknown and seems unusual in humans (Aptel et al., 2011, 2014b, 2016; Denis et al., 2015). RE has been described in $92 \%$ of dogs after cyclophotocoagulation (Hardman and Stanley, 2001) whereas it was only observed in $10 \%$ of cases after cyclophotocoagulation associated with an Ahmed gonioimplantation (Sapienza and van der Woerdt, 2005). RE was probably secondary to acute iatrogenic inflammation associated with cell damage (Hardman and Stanley, 2001) and may be reduced with the use of a gonioimplant, also allowing for lower laser energy applications (Sapienza and van der Woerdt, 2005). In our study, the post-operative hypertension spike and pain were observed in the same patient, which was a Shiba Inu. These complications might be due to inadequate positioning of the probe - the small palpebral fissure of Shiba Inu dogs making access to the eye difficult. Diffuse conjunctival hyperaemia was also visible in patients from groups 2 and 3 . These groups correspond to the highest levels of energy delivered to the eye, which might be responsible for diffuse conjunctival inflammation. Well circumscribed conjunctival burns were also visible in some patients. Although the ultrasound beam produced by the device was theoretically focused on the ciliary processes, there might be a localized heat dispersion leading to conjunctival lesions. Transient benign conjunctival hyperaemia was observed in humans and was more frequent in patients with higher levels of energy delivered to the eye (Denis et al., 2015). Other post- operative complications reported in humans and not observed in dogs were punctate keratitis, corneal ulcer, blepharitis and discrete uveal effusions (Aptel et al., 2011, 2014b, 2016; Denis et al., 2015).

In human patients, a duration-effect was observed with the sonication procedure. The hypotensive effect was higher when the ceramics delivered the ultrasounds over 6 seconds than over 4 seconds (Denis et al., 2015). As the duration was fixed in the veterinary probe, we decided to increase the number of sites to be treated as a function of the initial IOP. In human patients, the total amount of energy delivered to the ciliary processes depends on the number of treated sites and on the time of US delivery. The validated procedure treats 6 sites with a mean time of US delivery of 6 seconds, representing 6 × $6 \mathrm{~s}$ × $2.4 \mathrm{~W}=86,4 \mathrm{~J}$ (Aptel et al., 2011, 2014b, 2016; Denis et al., 2015). In our study, the total amount of energy was $72 \mathrm{~J}$ for group $1,96 \mathrm{~J}$ for group 2 and $120 \mathrm{~J}$ for group 3. Although the number of patients from group 3 was too low to reach statistical significance, our study suggests a higher IOP lowering effect in this group. To distinguish the respective roles of initial IOP level and the number of treatment sites on the IOP lowering effect, further study should evaluate the effect of the number of treatment sites in each baseline IOP ranges. The success rate of sonication for the treatment of PG was similar or better than the one of TSCP (alone (Hardman and Stanley, 2001) or combined with Ahmed valve implantation (Sapienza and van der Woerdt, 2005)) or ECP (alone (Azoulay et al., 2011) or combined with a X-Press gonioimplantation (Lutz and Sapienza, 2009b)). The levels of energy delivered to the eye were comparable to TCP (Hardman and Stanley, 2001; Sapienza and van der Woerdt, 2005; Amagai et al., 2014) but higher than with ECP (Lutz and Sapienza, 2009a,b; Azoulay et al., 2011; Harrington et al., 2013). However, the inclusion criteria were broader in our study, some eyes presenting with a smaller increase in IOP (IOP ranging from 21 to $25 \mathrm{~mm} \mathrm{Hg}$ ). In these eyes, the IOP normalization might also be due to the post-operative topical antiglaucomatous treatment. Further studies are necessary to compare the ocular hypotensive effect of sonication versus medical treatment alone. It might also be interesting to evaluate the hypotensive effect of HIFU alone (i.e. without medical therapy) on normotensive canine eyes and in patients with PG. The final aim of those complementary studies would be to assess the ability of the HIFU to reduce the risk of glaucoma in normotensive eye in patients at risk (prophylactic use on the fellow eye of patients with PG, or in patients presenting with a narrow/closed ciliary cleft). Our study only assessed the influence of HIFU on the IOP in dogs with PG. Further studies are warranted to evaluate the effect of HIFU on patients with secondary glaucoma (post intraocular surgery for example). 
In conclusion, our preliminary study suggests that HIFU cyclocoagulation might be a reasonable option for the management of PG in dogs. However, the number of patients included and the relatively short follow-up period preclude definitive conclusion, thus requiring larger prospective multicentric studies.

\section{Conflict of interest}

David Clément and Aurélie Béglé are currently employees of the EYE TECH CARE Company, which provided the veterinary prototype. None of the other authors has any conflict of interest.

\section{References}

Amagai, Y., Karasawa, K., Matsuda, H. and Tanaka, A. 2014. Diode laser transscleral cyclophotocoagulation in combination with trabeculectomy for surgical therapy of canine refractory glaucoma. J. Vet. Med. Res. 1, 1010.

Aptel, F., Charrel, T., Palazzi, X., Chapelon J.Y., Denis, P. and Lafon, C. 2010. Histologic effects of a new device for high-intensity focused ultrasound cyclocoagulation. Invest. Ophthalmol. Vis. Sci. 51, 5092-5097.

Aptel, F., Charrel, T., Lafon, C., Romano, F., Chapelon, J.Y., Blumen-Ohana, E., Nordmann, J.P. and Denis, P. 2011. Miniaturized high-intensity focused ultrasound device in patients with glaucoma: a clinical pilot study. Invest. Ophthalmol. Vis. Sci. 52, 8747-8753.

Aptel, F., Béglé, A., Razavi, A. Romano, F., Charrel, T., Chapelon, J.Y., Denis, P. and Lafon, C. 2014a. Short- and long-term effects on the ciliary body and the aqueous outflow pathways of high-intensity focused ultrasound cyclocoagulation. Ultrasound Med. Biol. 40, 2096-2106.

Aptel, F., Dupuy, C. and Rouland, J.F. 2014 b. Treatment of refractory open-angle glaucoma using ultrasonic circular cyclocoagulation: a prospective case series. Current Medical Research and Opinion. 30, 1599-1605.

Aptel, F., Denis, P., Rouland, J.F., Renard, J.P. and Bron, A. 2016. Multicenter clinical trial of highintensity focused ultrasound treatment in glaucoma patients without previous filtering surgery. Acta Ophthalmologica. 94, 268-277.

Azoulay, T., Dulaurent, T., Espejo, V., Goulle, F., Lazard, P. and Isard, P.F. 2011. The use of endocyclophotocoagulation of the ciliary processes for glaucoma: a review and series of 20 eyes. In the Proceedings of the 2011 Annual Meeting of the European Society of Veterinary Ophthalmologists, 03.

Bedford, P.G.C. 2017. Open-angle glaucoma in the Petit Basset Griffon Vendéen. Vet. Ophthalmol. 20, 98-102.

Bjerkas, E., Ekesten, B. and Farstad, W. 2002. Pectinate ligament dysplasia and narrowing of the iridocorneal angle associated with glaucoma in the English Springer Spaniel. Vet. Ophthalmol. 5, 4954.

Boillot, T., Rosolen S.G., Dulaurent, T., Goulle, F., Thomas, P., Isard, P.F., Azoulay, T., LafargeBeurlet, S., Woods, M., Lavillegrand, S., Ivkovic, I., Neveux, N., Sahel, J.A., Picaud, S. and Froger, N. 2014. Determination of morphological, biometric and biochemical susceptibilities in healthy Eurasier dogs with suspected inherited glaucoma. PLoS One. 9(11), e111873. doi: 10.1371/journal.pone.0111873.

Brightman, A.H., Vestre, W.A., Helper, L.C. and Tomes, J.E. 1982. Cryosurgery for the treatment of canine glaucoma. J. Am. Anim. Hosp. Assoc. 18, 319-322.

Burgess, S.E., Silverman, R.H., Coleman, D.J., Yablonski, M.E., Lizzi, F.L., Driller, J., Rosado, A. and Dennis, P.H. Jr. 1986. Treatment of glaucoma with high-intensity focused ultrasound. Ophthalmology 93, 831-838.

Charrel, T., Aptel, F., Birer, A. Chavrier, F., Romano, F., Chapelon, J.Y., Denis, P. and Lafon, C. 2011. Development of a miniaturized HIFU device for glaucoma treatment with conformal coagulation of the ciliary bodies. Ultrasound Med. Biol. 37, 742754.

Coleman, D.J., Lizzi, F.L., Driller, J., Rosado, A.L., Chang, S., Iwamoto, T. and Rosenthal, D. 1985a. Therapeutic ultrasound in the treatment of glaucoma. I. Experimental model. Ophthalmology 92, 339-346.

Coleman, D.J., Lizzi, F.L., Driller, J., Rosado, A.L., Burgess, S.E., Torpey, J.H., Smith, M.E., Silverman, R.H., Yablonski, M.E. and Chang, S. 1985b. Therapeutic ultrasound in the treatment of glaucoma, II: clinical applications. Ophthalmology 92, 347-352.

Coleman, D.J., Lizzi, F.L., Silverman, R.H., Dennis, P.H. Jr, Driller, J., Rosado, A. and Iwamoto, T. 1986. Therapeutic ultrasound. Ultrasound Med. Biol. 12, 633-638.

Cullen, C.L., Allen, A.L. and Grahn, B.H. 1998. Anterior chamber to frontal sinus shunt for the diversion of aqueous humor: a pilot study in four normal dogs. Vet. Ophthalmol. 1, 31-39.

Cullen, C.L. 2004. Cullen frontal sinus valved glaucoma shunt: preliminary findings in dogs with primary glaucoma. Vet. Ophthalmol. 7, 311-318.

Denis, P., Aptel, F., Rouland, J.F., Nordmann, J.P., Lachkar, Y., Renard, J.P., Sellem, E., Baudouin, C. and Bron, A. 2015. Cyclocoagulation of the ciliary bodies by high-intensity focused ultrasound: a 12month multicenter study. Invest. Ophthalmol. Vis. Sci. 56, 1089-1096. 
De Roetth, A. Jr. 1965. Cryosurgery for the treatment of glaucoma. Trans. Am. Ophthalmol. Soc. 63, 189204.

Fricker, G.V., Smith, K. and Gould, D.J. 2016. Survey of the incidence of pectinate ligament dysplasia and glaucoma in the UK Leonberger population. Vet. Ophthalmol. 19, 379-385.

Hardman, C. and Stanley, R.G. 2001. Diode laser transscleral cyclophotocoagulation for the treatment of primary glaucoma in 18 dogs: a retrospective study. Vet. Ophthalmol. 4, 209-215.

Harrington, J.T., McMullen, R.J. Jr., Cullen, J.M., Campbell, N.B. and Gilger B.C. 2013. Diode laser endoscopic cyclophotocoagulation in the normal equine eye. Vet. Ophthalmol. 16, 97-110.

Hassel, B., Samuelson, D.A., Lewis, P.A. and Gelatt, K.N. 2007. Immunocytochemical localization of smooth muscle actin-containing cells in the trabecular meshwork of glaucomatous and nonglaucomatous dogs. Vet. Ophthalmol. 10(Suppl. 1), 38-45.

Kato, K., Sasaki, N., Matsunaga, S., Mochizuki, M., Nishimura, R. and Ogawa, H. 2006. Possible association of glaucoma with pectinate ligament dysplasia and narrowing of the iridocorneal angle in Shiba Inu dogs in Japan. Vet. Ophthalmol. 9(2), 7175.

Lutz, E.A. and Sapienza J.S. 2009a. Diode endoscopic cyclophotocoagulation in pseudophakic and aphakic dogs with secondary glaucoma (abstract). In the Proceedings of the $40^{\text {th }}$ Annual Meeting of the American College of Veterinary Ophthalmologists, 051.

Lutz, E.A. and Sapienza, J.S. 2009b. Combined diode endoscopic cyclophotocoagulation and Ex-Press ${ }^{\circledR}$ shunt gonioimplantation in four cases of canine glaucoma (abstract). In the Proceedings of the $40^{\text {th }}$ Annual Meeting of the American College of Veterinary Ophthalmologists, 050.

Mackay, E.O., Källberg, M.E. and Gelatt K.N. 2008a. Aqueous humor myocilin protein levels in normal, genetic carriers, and glaucoma Beagles. Vet. Ophthalmol. 11, 177-185.

MacKay, E.O., Kallberg, M.E., Barrie, K.P., Miller, W.,
Sapienza, J.S., Denis, H., Ollivier, F.J., Plummer, C.E., Rinkoski, T., Scotty, N. and Gelatt, K.N. 2008b. Myocilin protein levels in the aqueous humor of the glaucomas in selected canine breeds. Vet. Ophthalmol. 11, 234-241.

Plummer, C.E., Regnier, A. and Gelatt, K.N. 2013. The Canine Glaucomas. In: Veterinary Ophthalmology, $5^{\text {th }}$ edn, Eds. Gelatt, K.N., Gilger, C.G. and Kern, T.J. Wiley-Blackwell, Ames, pp: 1050-1145.

Polack, P.J., Iwamoto, T., Silverman, R.H., Driller, J., Lizzi, F.L. and Coleman, D.J. 1991. Histologic effects of contact ultrasound for the treatment of glaucoma. Invest. Ophthalmol. Vis. Sci. 32, 21362142.

Read, R.A., Wood, J.L. and Lakhani, K.H. 1998. Pectinate ligament dysplasia (PLD) and glaucoma in Flat Coated Retrievers. I. Objectives, technique and results of a PLD survey. Vet. Ophthalmol. 1, 8590.

Sapienza, J.S. and van der Woerdt, A. 2005. Combined transscleral diode laser cyclophotocoagulation and Ahmed gonioimplantation in dogs with primary glaucoma: 51 cases (1996-2004). Vet. Ophthalmol. $8,121-127$.

Strom, A.R., Hässig, M., Iburg, T.M. and Spiess, B.M. 2011. Epidemiology of canine glaucoma presented to University of Zurich from 1995 to 2009. Part 1: Congenital and primary glaucoma (4 and 123 cases). Vet. Ophthalmol. 14, 121-126.

Valtot, F., Kopel, J. and Le Mer, Y. 1990. Principles and histologic effects of the treatment of hypertension with focused high-intensity ultrasound. Ophtalmologie 4, 135-137.

Weinstein, W.L., Dietrich, U.M., Sapienza, J.S., Carmichael, K.P., Moore, P.A. and Krunkosky, T.M. 2007. Identification of ocular matrix metalloproteinases present within the aqueous humor and iridocorneal drainage angle tissue of normal and glaucomatous canine eyes. Vet. Ophthalmol. 10(Suppl. 1), 108-116.

Wood, J.L., Lakhani, K.H. and Read, R.A. 1998. Pectinate ligament dysplasia and glaucoma in Flat Coated Retrievers. II. Assessment of prevalence and heritability. Vet. Ophthalmol. 1, 91-99. 